\title{
Improving the Applicability of Environmental Scanning Systems: State of the Art and Future Research
}

\author{
Jörg H. Mayer ${ }^{1}$, Neon Steinecke ${ }^{2}$, and Reiner Quick ${ }^{2}$ \\ ${ }^{1}$ University of St. Gallen, Mueller-Friedberg-Strasse 8, 9000 St. Gallen, Switzerland \\ Tel.: +41 (0) 712242190 \\ joerg.mayer@unisg.ch \\ ${ }^{2}$ Darmstadt University of Technology, Hochschulstrasse 1, 64289 Darmstadt, Germany \\ Tel.: +49 (0) $6151163423,+49$ (0) 6151163423 \\ neon.steineckedstud.tu-darmstadt.de \\ quick@bwl.tu-darmstadt.de
}

\begin{abstract}
The 2008/2009 economic crisis provided a sustainable impulse for improving environmental scanning systems (ESS). Although a rich body of know-ledge exists, concepts are not often used in practice. This article contributes a literature review addressing six findings for ESS design to become more applicable than the state of the art. They are structured by the elements of information systems (IS) design theories. Addressing the lack of a sound requirements analysis, our first finding proposes 360-degree ESS for executives' "managing a company" task and presents how to select just the most important scanning areas to keep focus. Three other findings cover the IS model perspective focusing on a better "grasp" of weak signals: define concrete indicators and use IT to identify relevant cause-effective-chains, leverage IT to automate dayto-day routines and monitor the variety of indicators' movements, and-as a fourth finding-leverage expert experience with an impact matrix and translate indicators' impact into a balanced opportunity-and-threat portfolio. From the methods perspective on ESS, we propose to more closely incorporate scanning results into executives' decision-making process by generating scenarios from a set of environment assumptions as well as to use retrospective controls to continuously update the ESS and collaborate to share the scanning findings day-to-day.
\end{abstract}

Keywords: Corporate management, balanced chance and risk management, information and communication technology (ICT), literature review.

\section{Introduction}

Environments' increasing volatility is a growing concern for companies. Executives worry about not being prepared for environmental shifts or-even worse-not being able to parry them. The 2008/2009 economic crisis gave a sustainable impulse for focusing earlier on emerging threats and opportunities (Hopwood 2009; Makridakis et 
al. 2010). Environmental scanning-ideally, IT-based within a corporate business intelligence (BI) architecture (Wixom et al. 2010) ${ }^{1}$ — can help to manage this challenge. Companies that do so will have brighter prospects than those that do not (Ansoff 1980).

With Ansoff's (1975) article "Managing Strategic Surprise by Response to Weak Signals" as an example, a rich body of knowledge exists, but it often goes unused. Practitioners perceive the task as a difficult one per se (Lesca et al. 2008). Some may not even know how to start (Albright 2004). They experience difficulties in designing, implementing, and operating environmental scanning systems (ESS). The objective of this article is therefore to design such information systems (IS) that are more applicable than the state of the art (Sec. 5.2).

As this work represents a first step in a larger research project, we start with a review of related work for big picture thinking and define future research to follow for more applicable ESS. Generally based on the Webster and Watson (2002) approach to literature review, we follow vom Brocke et al.'s (2009) five-step procedure. Definition of review scope: We motivate this article by reporting gaps between the rich body of knowledge and survey results suggesting that these concepts are often not used in practice. Conceptualization of topic: After revisiting foundations (Sec. 2), we show the need of ESS (Sec. 3). Hereafter we derive a framework for categorizing the literature (Sec. 4). Literature search and analysis: We then lay open our literature search process (Sec. 5.1). Out of 80 publications surveyed, we describe the most important ones providing accepted knowledge (Sec. 5.2). Literature synthesis: Based on the findings, we develop a future research agenda (Sec. 6). We close with a summary, the limitations of our work and ongoing research (Sec. 7).

\section{Foundations}

A company's environment could be defined as the relevant physical and social factors within and beyond the organization's boundary (Duncan 1972). While operational analysis focuses on internal difficulties in the implementation of strategic programs with the aim of fully leveraging identified potential, strategic environmental scanning, in turn, aims at anticipating (long-term) environmental shifts and analyzing their potential impact.

This research concentrates on the latter referred to as "environmental scanning". Its main function is to gather, interpret, and use pertinent information about events, trends, and relationships in an organization's environment that would assist management in planning the future course of action (Aguilar 1967).

As an IS label to support managerial decision making, management support systems $^{2}$ (MSS) are proposed in literature. They cover decision support systems

${ }^{1} \mathrm{BI}$ is a broad category of technologies, applications, and processes for gathering, storing, accessing, and analyzing data to help its users make better decision (Wixom et al. 2010).

${ }^{2}$ Both, MSS (Clark Jr. et al. 2007) and DSS (Arnott et al. 2008) have been proposed as labels for IS intended to provide IT support for managerial decision making. Since DSS evolved from a specific concept that originated as a complement to MIS and was overlapped in the late 1980s with EIS, we refer to MSS on hand (Power 2008). 
(DSS), management information systems (MIS), executive information systems (EIS), more recently knowledge management systems (KMS), and BI systems (Clark Jr. et al. 2007). ESS, in turn, have their roots in management literature focusing on the executives' task to be aware of environmental trends (Aguilar 1967). They specify the sectors to-be scanned, monitor the most important indicators that may create opportunities or threats for the organization, cover the IS-based tools to be used (YasaiArdenaki et al. 1996), incorporate the findings of such analyses into executives' decision making, and often assign responsibilities to support environmental scanning (not covered in this article, but in Lenz et al. 1986).

Two information collection modes are distinguished (Choudhury et al. 1997): In contrast to the reactive mode in which information is acquired to resolve a problem, we follow the proactive mode in which the environment is scanned for upcoming changes that represent opportunities and threats (Fahey et al. 1977). As a result, this article aims at ESS, which are conceived as structured, reticulated IT-based IS to allow executives to scan their environment from an overall perspective for a proactive corporate management.

\section{Need for Improving Environmental Scanning Systems}

Regulatory needs: Environmental scanning is not just "nice to have", as Kajüter (2004) shows in his multicountry comparison. In the wake of several cases of fraud around the turn of the millenium that were neither detected by internal controls nor by auditors, legislators expressed a need for a more detailed risk management approach. Best known is the U.S. Sarbanes-Oxley-Act. In particular Section 404, requires companies listed on the New York Stock Exchange to extensively document internal controls, establish independent audit committees, and have internal controls' effectiveness audited mandatory (Sherman et al. 2009). Furthermore, financial statements are normally prepared on the assumption that a company will continue in operations for the foreseeable future (IASB Framework 4.1; ISA 1.25). This requires predictions of at least one year (Choo 2009). In the wake of the 2008/2009 economic crisis, the assessment of this "going-concern" has gained an increased importance.

Empirical evidence: Fuld (2003) showed the lack of an early warning system in $97 \%$ of the U.S. companies he surveyed. Interviews with 140 corporate strategists found that two-thirds had been surprised by as many as three high-impact competitive events in the past five years. Following Krystek \& Herzhoff (2006), 30\% of European chemicals companies do not have strategic ESS in place. $15 \%$ said that the instruments available are not sufficiently accepted to be used in practice. Day \& Schoemaker's (2005) survey of global managers found that $81 \%$ perceived their future need for peripheral vision to be greater than their current capacity. Similar findings are reported from companies within the Financial Times "Europe 500" report (Mayer 2010): most of the executives consider environmental-scanning concepts to be too complex and even too difficult to implement. Therefore, results are not a substantial part of executive decision-making process. 


\section{Framework for Literature Systematization}

Following Webster and Watson (2002) a literature review is concept-centric. Elements of IS design theories in combination with the research method used offer a framework for structuring the literature (Figure 1).

\subsection{Elements of IS Design Theories}

According to Walls et al. (1992), IS design theories consist of three elements: (1) Requirements can be defined as prerequisites, conditions, or capabilities needed by users of software systems to solve a problem or achieve an objective (IEEE610.121990). They delineate what IS should do, both from the functional and non-functional perspective (Kotonya et al. 1998). Functional requirements address "what" IS should or must do (purpose of the IS). Non-functional requirements, in contrast, reflect "how well" IS perform within the given environment as it fulfills its function, e.g. response time and reliability (Paech et al. 2004).

Designing ESS is not a Greenfield approach. For that reason, IS design theories cover guidelines for bringing the system to life. They contribute to methods and models. (2) Models outline concrete systems, features, or combinations of these (Gregor 2006). We distinguish between forecasting as the first generation of ESS, indicatorbased systems as the second one, and environmental scanning using weak signals as the third generation. (3) Methods cover the process of environmental scanning. We differentiate between information gathering ("scanning"), analytical techniques to identify latent or pending changes; and the incorporation of the scanning results into executives' decision-making process.

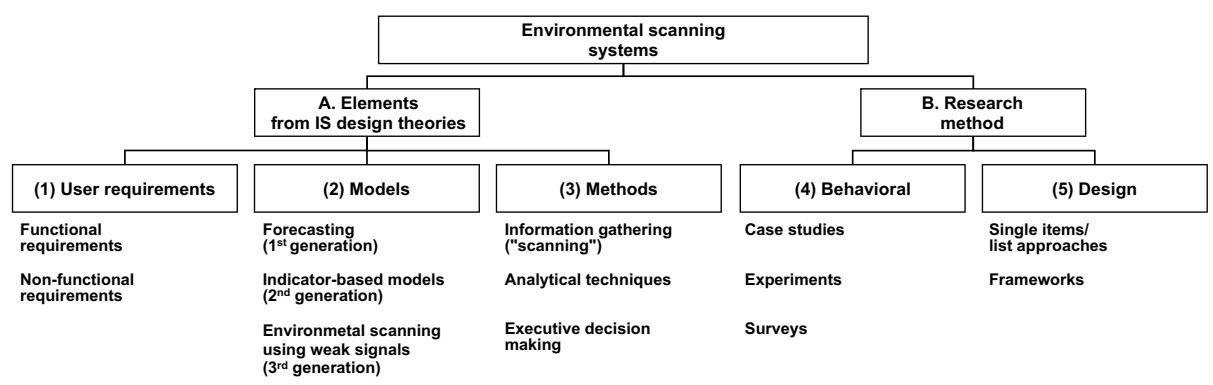

Fig. 1. Framework for literature systematization

\subsection{Research Methods}

The type of research method is another dimension in our framework for systematizing the literature. Their distinction is important as it influences the granularity of requirements and design principles: from abstract findings by a survey regarding "appropriate technology" to detailed IS features from an in-depth case study such as "drill-down functionality to an upstream ERP" (Urbach et al. 2009). 
(4) Papers with a behavioral focus explain phenomena from practice. Therefore, they rely on observations and focus on some type of empirical method. We differentiate between case studies to learn from single design, experiments, and surveys (Urbach et al. 2009). (5) Design approaches involve ideas and frameworks for creating a better world and provide more direct recommendations for IS (Walls et al. 1992). We go on differentiating between single items and broader "list" approa-ches that specify sets of requirements, design principles and frameworks that focus on the relationship between requirements and design principles.

\section{Literature Analysis}

Generally based on the Webster and Watson (2002) approach to literature review, we introduce our search strategy (Sec. 5.1). Then, we systematize the results to discuss the most important publications at a glance (Sec. 5.2). The synthesis of findings follows in Sec. 6.

\subsection{Search Strategy}

Following vom Brocke et al. (2009), we first perform a journal search. We focus on leading IS research outlets and select six of the most relevant IS journals ${ }^{3}$ reflecting their ranking ${ }^{4}$ and impact factor ${ }^{5}$ (Webster et al. 2002). Furthermore, we expand our list with proceedings from the two A-ranked international conferences listed by WKWI (2008): the International and European Conferences on IS (ICIS, ECIS). Second, we use EBSCO host, Google scholar, Science Direct, and Wiley Inter Science to access the journals. Third, the keywords "environmental scanning system" and "early warning system, weak signal, leading indicator" produce 14 relevant hits in total. Fourth, by doing a backward and forward search, we add the keywords "management support systems" and "business intelligence" to our search string, leading to additional 13 IS articles. Finally, we did the same search on strategic management literature ${ }^{6}$ coming up with another 53 hits. So, we end up with 80 relevant publications in total (Figure 2, in detail Table A1).

\subsection{Results}

Figure 3 presents the 80 publications identified as relevant within the framework we derived before. The most revealing publications are discussed below. The insights then allow us to develop the findings for ESS more applicable than the state of the art (Sec. 6).

${ }^{3}$ MIS Quarterly, Decision Support Systems, Information \& Management, Journal of Management Information Systems, European Journal of Information Systems, and Information System Management.

${ }^{4}$ Based on journal rankings of AIS (2010); VHB (2008); WKWI (2008).

${ }^{5}$ We considered impact factors from http://www.elsevier.com

${ }^{6}$ Strategic Management Journal (SMJ), Long Range Planning (LRP), Journal of Management Studies (JMS), Technology Analysis and Strategic Management (TASM), Academy of Management Review (AMR), Harvard Business Review (HBR) 


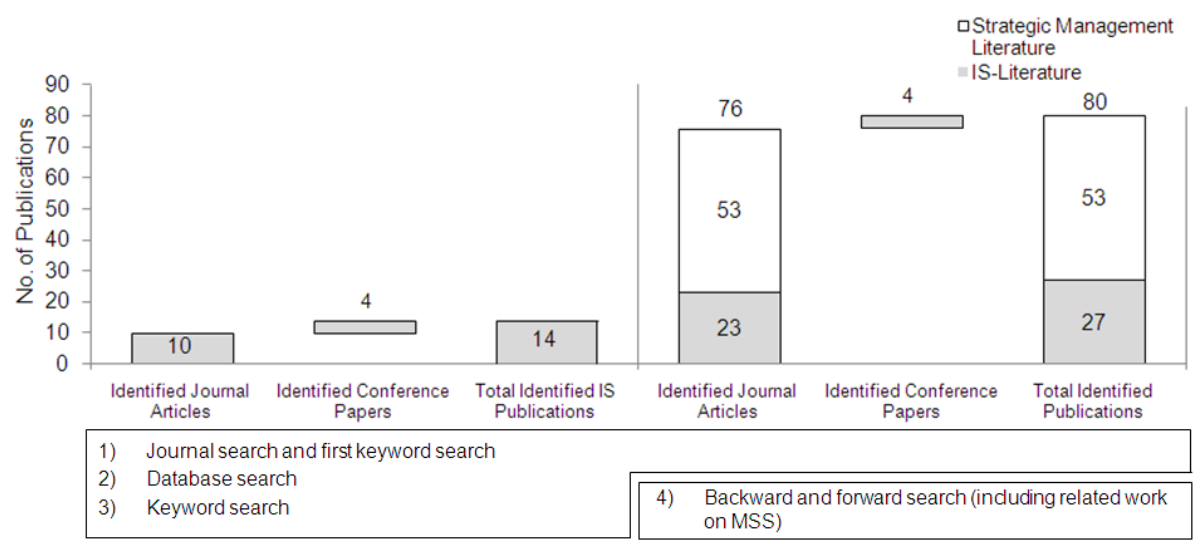

Fig. 2. Selection of the relevant publications

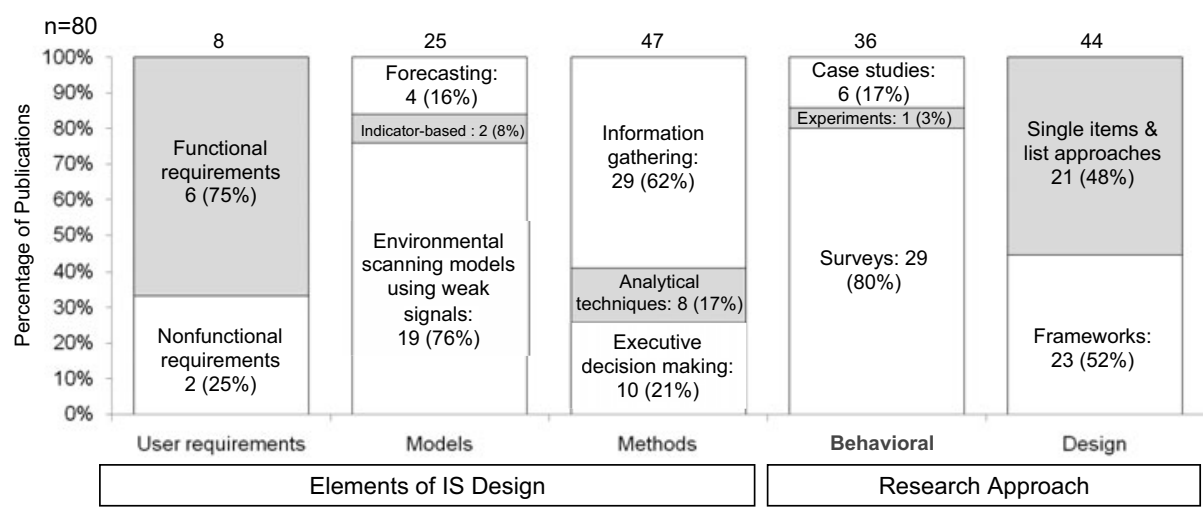

Fig. 3. Classification of the publications

\section{User requirements}

Just six out of 80 publications focus on functional requirements and an even minor number of two on non-functional ones. Of particular relevance is Xu et al. (2003). To develop a Corporate Radar, these authors conducted a cross-industry study and found that task-related environmental areas are perceived to be more important than fargeneral environmental in-formation. For example, in the computer and electronics industry the supplier sector was assessed as a fundamental area for environmental scanning.

Another five studies reviewed functional requirements of executives by their scanning practices. For example, Yasai-Ardenaki \& Nystrom (1996) emphasize a link between scanning areas and strategy. Especially in volatile industries, the "periphery" - a metaphor, describing latent changes that can come e.g. from political movements - should be considered for environmental scanning (Day et al. 2004). Regarding Daft et al. (1988) the periphery should cover at least science, politics, law 
and justice and international relationships. Focusing the non-functional perspective, El Sawy (1985) dealt with executives scanning requirements and suggests that a successful solution should have just a limited number of scanning areas and sources.

\section{Models}

Out of our 80 articles, 25 publications cover models for environmental scanning. They can be divided into three generations: Early warning systems were first mentioned in the late six-ties by Cohen \& Zinbarg (1967). These key-figure-oriented approaches are based on thresholds that define the range of tolerance. If a critical value is exceeded, an alert is triggered. Forecasting advances this technique using time series, not only for planned and actual data, but also planned and extrapolated as-is data.

Second generation ESS identify latent risks and chances. Such an indicator-based model is described by Davies et al. (2006). Their key risk indicators (KRI) are standardized indicators that focus on potential problems, e.g., staff turnover could signal inadequate human resources performance. Since random or natural fluctuations occur, they recommend reference values and ranges of tolerance to avoid overreactions.

After companies failed to act proactively on the oil-crisis, Ansoff introduced the concept of weak signals in 1975. An example is the World Wide Web (www) changing the private and business communication or the spread of carbon fibre. The latter's usage for example has increased steadily in recent years and its potential to serve as a substitute for steel represents a strategic issue for steelmakers. As we see nowadays, weak signals do not always work out. They often lack "grasp" for direct interactions. But Ansoff's concept is still topical in recent literature. In fact, $76 \%$ of publications about models use his approach. Narchal et al. (1987) promise that a systematic scanning and monitoring is more effective than ad hoc scanning in giving a prognosis of future developments. Hereby, they stress descriptors indicating relevant developments, trends, and events in the environment. They explain and quantify dynamics within the scanning areas.

\section{Methods}

Aguilar (1967) was the first to examine four different modes of scanning, namely undirected viewing, conditional viewing, informal search and formal search. Attaining strategic advantages by information gathering have been of high interest and therefore $62 \%$ of articles on methods refine the concept.

Several analytical techniques for environmental scanning are distinguished in literature and covers $17 \%$ of the publications researched: mathematical methods facilitate a systematic integration of quantifiable figures into ESS. But, the 2008/2009 economic crisis showed that they had significant scarcities for ordinary users. Often premises were too complicated (Ma-kridakis et al., 2010) or the use of confidence intervals in value-at-risk models excludes improbable, high-impact events (Fuld, 2003). Taleb et al. (2009) also criticize these models, because even small errors in the assumptions underlying the distributions can be devastating. Heuristic approaches are alternatives (Ansoff 1980). For example, the delphi method comprises three features: First, responses from experts to a topic are anonymous, usually using formalized questionnaires. Second, in several iterations, feedback is given to the experts. Third, 
after a few iterations, when the results stabilized, group response is aggregated (Dalkey 1969). Narchal et al. (1987) recommend influence diagrams focusing on levers and their influence on the most important environmental indicators. In order to model dependencies between single items, cross-impact matrices evolved (Fontela 1976). It is also argued that such matrices can contribute to find a most probable scenario of the future.

One dimensional performance measurement systems often do not suffice to meet the complete information need. More important, Fuld (2003) showed that companies often fail to act on generated environmental scanning information, either by measuring the impact of identified opportunities and threats on (financial) performance indicators or incorporating the results of ESS in executives' decision making process per se. Frolick et al. (1997) argue to embed EIS into the environmental scanning process. EIS can enhance identifying issues, establishing means of scanning, delineating sources of external information and decision making. Finally, they can help to incorporate anticipated changes in the planning and reporting.

\section{MSS and environmental scanning}

To complement our results, we also consider findings from contemporary related MSS work. Gleißner \& Füser (2000) propose artificial neural networks to support early warning capabilities in corporations. In contrast to humans, they are not limited by psychological barriers. Moreover they can deal with many different variables coincidentally - as needed to handle the potential span of indicators. They are adaptive and robust models. Thus, they are widely used for fraud detection (Ngai et al. 2011), but not used in environmental scanning.

Using value at risk ( $\mathrm{VaR}$, Chen et al. 2011) and unstructured data from BI can predict financial market risk and thus should contribute to environmental scanning. Recent developments in the www, namely web 2.0, and incorporated social networking, provide useful in-formation on customers and competitors. For example, customers that judge their goods bought offer useful strategic information on products quality and future offers (Chen et al. 2011). Besides the internet, also capital markets provide useful information on customers, suppliers, competitors, and the economic development (Plambeck \& Weber 2010). They can deliver future perspectives, e.g. on growth rates of economies or net sales of organizations.

Understanding BI in a broader sense, Goul and Corral (2007) ask for data warehouses (DWH) to include information about external issues such as competitors or regulations and to provide measurability of the strategic advantages. Lönnqvist and Pirttimäki (2006) performed a literature review to evaluate existing methods for measuring the value of $B I$ within the organization. For example user satisfaction gives an insight. Those measurement approaches should be checked for applicability to evaluate ESS.

\section{Synthesis}

The literature systematization in Sec. 5 reveals major gaps in research to overcome for more applicable ESS. Interpreting them, we go on with six findings for a reworked 
IS (also Mayer 2011). Herein, we incorporate first ideas from Narchal et al. (1987) and Mayer and Wurl (2011). The latter refer to it as the Corporate Radar. An instantiations at a large, international companies in the basic materials sector (Europe, sales: USD 56 bn; employees: 174,000) helped us to make the findings more concrete.

\subsection{User Requirements: Lack of Sound Requirements Analysis}

Just six out of 80 publications focus on functional requirements and an even smaller number of two on non-functional requirements. Some may argue that improvisation could be an alternative approach (Ciborra 1999), but following the homo oeconomicus theory we believe the best way to tackle the increasingly volatile environment is reasoning on cause and effect chains. Thus, a series of indicators have to be collected in order to detect threats and opportunities to anticipate for proactive corporate management.

A first finding can be proposed as follows: Take a 360-degree approach to support executives' "managing a company" task, but select just the most important scanning areas to keep focus. When designing ESS, we recommend starting with the most popular and wide-spread conceptual design of $\mathrm{Xu}$ et al. (2003) and prioritize taskrelated environmental areas. Because executives have the task of managing a company, a "360 degree" radar is needed (Figure 4). It should reflect the organization's vision and strategic program (Yasai-Ardenaki et al. 1996) and then follow the value chain for their scanning areas of procurement, production and sales (Day et al. 2005). Following El Sawy (1985) and his non-functional perspective on requirements that just the most important scanning areas should be considered to keep focus, most important supporting areas are capital supply, research and development, and human resources. The more volatile the company's environment, the more the peripheral areas should be scanned. Following the PESTL scheme e.g. (Daft et al. 1988), such peripheral areas are legal and compliance or shifts in social or political behaviour. IS support for this first activity of setting up a Corporate Radar is not mandatory.

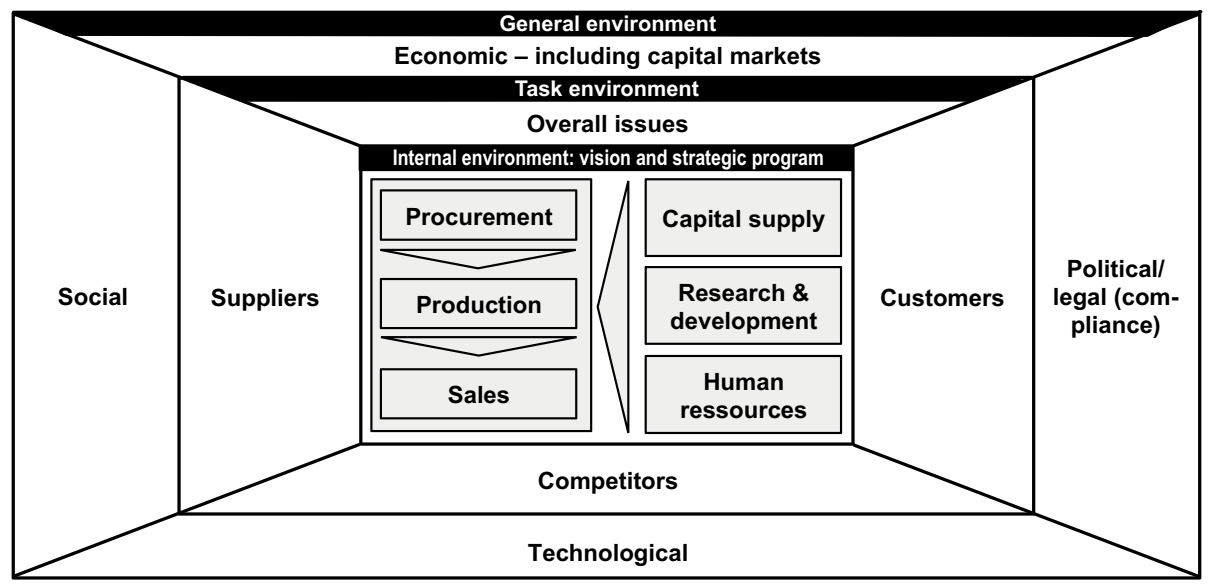

Fig. 4. Scanning areas for reworked environmental scanning systems 


\subsection{Models: Weak Signals Lack the "Grasp" to Apply in Practice}

The most popular and widespread approach to find indicators giving executives the time for proactive decision making are weak signals (Figure 3). So we stick to that concept with the aim to improve their missing "grasp" which we identified in the literature systemization. What changes in organizations' environment are weak signals and so proactively show significant turbulences is unclear. Especially weak signals differentiation from day-to-day vibrations without consequences is difficult. With the following three findings we translate Ansoffs' weak signals in a more pragmatic IT-based approach of indicators.

Second finding: Define concrete indicators and use IS to identify relevant causeeffective-chains. Based on our literature review, we see two levers to improve weak signals "grasp": first, distinguishing relevant indicators foreseeing changes from the mass of data available (Narchal et al. 1987) and give guidelines on how to identify patterns attaining their strategic advantages for the organization (Aguilar 1967). Following Davies (2006), we propose as evaluation criteria indicators' lead time, clarity, and their appropriate cost-/impact ratio. For example if sales is an important scanning area, the Baltic dry index, which measures the rates charged for dry-bulk vessels, could be used to indicate overall economic development.

Second, the barriers preventing people from identifying and processing weak signals can be circumvented with IS (Hand 2009). Structuring data, artificial neural networks, data mining, and semantic search should receive greater attention as ways to extract cause-effective-chains (Elofson et al. 1991). So, IS researchers should therefore focus on exploring techniques to extract non-trivial, implicit, previously unknown and potentially useful patterns.

Third finding: Leverage IT to automate day-to-day routines and to follow the variety of indicators' movements. In a third step, data sources and the frequency of data collection must be determined. A trade-off is necessary between the cost of data collection, such as license fees of data sources, costs of additional employees, the reporting system itself and its ability to indicate potential opportunities and threats. We particularly emphasize the Internet (Chen et al. 2011) as well as capital markets (Plambeck \& Weber 2010) as data sources, because they have an inherent good cost/benefit ratio at least for basic information generation. The use of supportive, predefined and easyto-handle user interfaces for data access or common IT languages, such as XBRL (eXtensible Business Reporting Language), facilitate accessing relevant information sources by automated routines to systematically monitor the movements of the most important indicators. To save even more cost and time to process information gathering data through computerized notes is proposed (Frolick et al. 1997).

Fourth finding: Leverage expert experience with an impact matrix and translate indicators' impact into a balanced opportunity-and-threat portfolio. To model the indicators' impact, instead of using complex mathematical models, we propose a heuristic approach based on the delphi method. This is for the reason that a basic understanding of risks and their implications on organizations' performance is more important than pseudo-exact calculations with difficult mathematical approaches. Within the delphi method for ESS, experts should be asked to qualify indicators' impact on threats and 
opportunities (Mayer and Wurl 2011). On the left hand side in Figure 5 the indicators, their scoring according to threats and opportunities (x-axis) and their estimated lead time (y-axis), are shown. The bundling is used to derive the associated opportunities and threats for the organization (right hand side): The balanced opportunity-and-threat portfolio draws on the results of an analysis quantifying the impact of each individual indicators on the most important threats and opportunities (Fontela 1976). We choose this visualization because it is comprehensive in terms of content, but in terms of presentation it represents a condensed overview about most important opportunities and threat for the organization.

\subsection{Methods: Approaches Lack to Incorporate Results of Environmental Scanning Systems into Executives' Decision Making}

Last, but not least, the third gap that becomes obvious is that environmental scanning is useless, as long as the results are not integrated in executives' decision-making processes. We derive another two findings for improving ESS towards more applicability from the method perspective.

Fifth finding: Incorporate scanning results more closely into executives' decisionmaking process by generating scenarios from a set of environment assumptions. To ensure that executives receive scanning findings in an amount and form that facilitates effective decision making, their reporting should cover critical opportunities and threats. For a periodical presentation, we propose linking the identified opportunities and threats with a companies' management control (Ansoff 1980; Frolick et al. 1997). We propose the form of an economic value added at risk tree (Chen et al. 2011, Figure 6). Once the indicators and the associated opportunities and threats have been identified, they should define three scenarios (Fontela 1976)

-optimistic, most probable and pessimistic - covering the set of opportunities and threats that the organization faces due to environmental changes (Narchal et al. 1987).

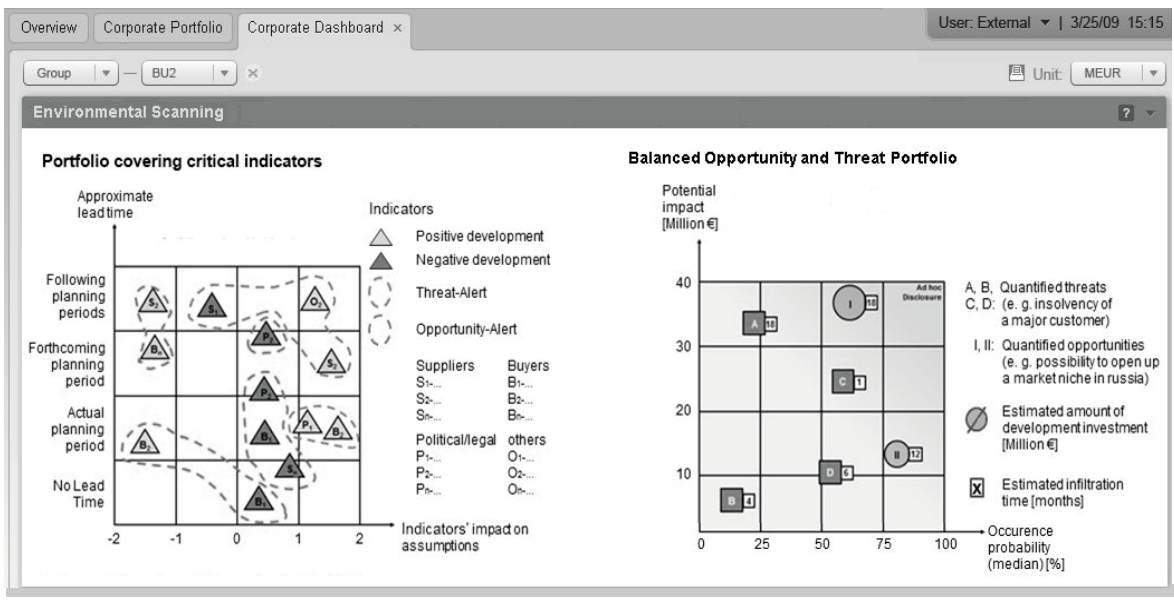

Fig. 5. Deriving and quantifying opportunities and threats in a balanced opportunity-and-threat portfolio 
New business application and user-friendly interface ("frontend") should provide the scenario visualization that allows switching between the best, worst and most probable scenarios (Figure 6, right hand side). The best and worst case scenarios define the range of the most important value drivers such as net sales and costs. Because of the mathematical connections between them, also ranges for the financial performance indicators EBIT, ROCE and EVA (Figure 6, left hand side) are defined as well. The slider position shown here represents the most probable scenario. All drivers can be moved to the right or to the left to simulate changes no matter which scenario is selected. Furthermore, on an ad-hoc basis, "breaking news" and "turning points" that refute prior assumptions can be helpful.

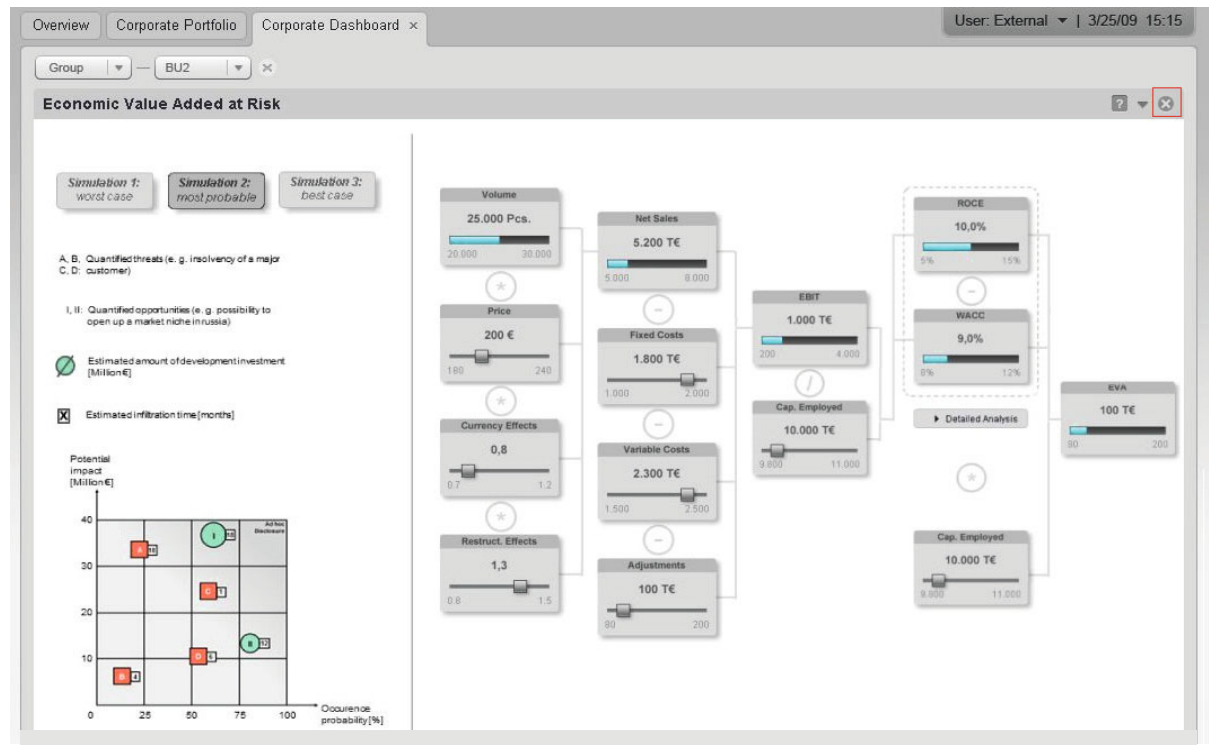

Fig. 6. Incorporating the results of ESS into executives' decision making by scenario technique (first instantiation)

Sixth finding: Use retrospective controls to continuously update the IS and collaborate to share the scanning findings in day-to-day work. Assumptions should be verified and methods applied should be checked for modifications due to new findings. In day-to-day work, group-ware allows e-mailing and other forms of collaboration.

\section{Outlook and Future Research}

The objective of this article was to contribute to developing ESS that are more applicable than the state of the art. To do so, we conducted a literature analysis structured by the elements of IS design theories. We came up with three gaps to overcome and six findings. 
Comparing the findings with the state of the art reveals some points worthy of discussion. On the one hand, literature based findings offer greater rigor than action research does. Thus, they should be more sustainable. However, our research has been limited to a restricted number of publications. But, the fact that we covered the leading journals means major contributions should be included. We see the need to expand this coverage, especially by identifying practitioner publications that are not listed in the top IS and management literature we researched or publications that do not include any of our search terms. Another limitation is that the synthesis entails subjectivity. In short, the validity of the derived findings could have been increased if more researchers had been involved.

Regarding IS in environmental scanning, we expect ongoing innovations. Today's executives grew up with IT and have a more natural attitude toward IS. New technologies have been established in the field of corporate BI, such as EIS, which have evolved from a single-system approach to an integrated module in powerful data warehouse environments. More-over, new user interfaces and end-user devices, especially for mobile computing, should simplify IS handling. Hence, ESS should claim a position in the domain of MSS (Sec. 2) as it focusing on forward looking information for managers to plan and steer their organizations.

For future research it is important to specify the findings on hand with "build" and "evaluate" activities. Another contribution could be a survey to get a direct perspective on executives' requirements and to evaluate the findings in a broad sample. If someone may come to the conclusion that the body of knowledge from literature research is more wishful thinking than a sound basis for applicable design principles it would be interesting to define a set of evaluation criteria, take successful implementations from practice, evaluate them, ascertain what they have in common and compare these findings with the first design principles presented on hand. Our own research will use additional instantiations to determine the generalizability of the findings on hand and, hopefully, the forthcoming extensions.

\section{References}

Aguilar, F.J.: Scanning the Business Environment. Macmillan, New York (1967)

Albright, K.S.: Environmental scanning: radar for success. The Information Management Journal 38(3), 38-45 (2004)

Ansoff, H.I.: Managing Strategic Surprise by Response to Weak Signals. California Management Review 18(2), 21-32 (1975)

Ansoff, H.I.: Strategic Issue Management. Strategic Management Journal 1(2), 131-148 (1980)

Arnott, D., Pervan, G.: Eight key issues for the decision support systems discipline. Decision Support Systems 44(3), 657-672 (2008)

Choo, C.W.: Information Use and Early Warning Effectiveness: Perspectives and Prospects. Journal of the American Society for Information Science and Technology 60(5), 1071-1082 (2009)

Choudhury, V., Sampler, J.L.: Information Specificity and Environmental Scan-ning: An Economic Perspective. MIS Quarterly 21(1), 25-53 (1997)

Ciborra, C.: Notes in Improvisation and Time in Organizations. Accounting, Management and Information Technologies 9(2), 77-94 (1999) 
Clark Jr., T.D., Jones, M.C., Armstrong Curtis, P.: The Dynamic Structure of Management Support Systems: Theory Development, Research Focus, and Direction. MIS Quarterly 31(3), 579-615 (2007)

Cohen, J.B., Zinsbarg, E.D.: Investment Analysis and Portfolio Management. Dow JonesIrwing Inc., Homewood (1967)

Daft, R.L., Sormunen, J., Parks, D.: Chief Executive Scanning, Environmental Characteristics, and Company Performance: An Empirical Study. Strategic Management Journal 9(2), 123 139 (1988)

Dalkey, N.C.: The Delphi Method: An experimental study of group opinion. Rand, Santa Monica (1969)

Davies, J., Finlay, M., McLenaghen, T., Wilson, D.: Key Risk Indicators - Their Role in Operational Risk Management and Measurement. In: ARM and RiskBusiness International, Prague, pp. 1-32 (2006)

Day, G.S., Schoemaker, P.J.H.: Driving through the Fog: Managing at the Edge. Long Range Planning 37(2), 127-142 (2004)

Day, G.S., Schoemaker, P.J.H.: Scanning The Periphery. Harvard Business Review 83(11), 135-148 (2005)

Duncan, R.B.: Characteristics of Organizational Environments and Perceived Environmental Uncertainty. Administrative Science Quarterly 17(3), 313-327 (1972)

El Sawy, O.A.: Personal Information Systems for Strategic Scanning in Turbulent Environments: Can the CEO Go On-Line? MIS Quarterly 9(1), 53-60 (1985)

Elofson, G., Konsynski, B.: Delegation technologies: Environmental scanning with intelligent agents. Journal of Management Information Systems 8(1), 37-62 (1991)

Fahey, L., King, W.R.: Environmental Scanning for Corporate Planning. Business Horizons 20(4), 61 (1977)

Fontela, E.: Industrial Applications of Cross-Impact Analysis. Long Range Planning 9(4), 29 33 (1976)

Frolick, M.N., Parzinger, M.J., Rainer Jr., R.K., Ramarapu, N.K.: Using EISs for environmental scanning. Information Systems Management 14(1), 35-40 (1997)

Fuld, L.: Be Prepared. Harvard Business Review 81(11), 20-21 (2003)

Gregor, S.: The Nature of Theory in Information Systems. MIS Quarterly 30(3), 611-642 (2006)

Hand, D.J.: Mining the past to determine the future: Problems and possibilities. International Journal of Forecasting 25(5), 441-451 (2009)

Hopwood, A.G.: The economic crisis and accounting: Implications for the research community. Accounting, Organizations \& Society 34(6/7), 797-802 (2009)

IEEE 1990. The Institute of Electrical and Electronics Engineers, Inc. - Standard Glossary of Software Engineering Terminology. IEEE Computer Society, New York (1990)

Kajüter, P.: Die Regulierung des Risikomanagements im internationalen Vergleich. Zeitschrift für Controlling und Management 47(Sonderheft 3), 12-25 (2004)

Kotonya, G., Sommerville, I.: Requirements Engineering Processes and Techniques. John Wiley \& Sons Ltd., Hoboken (1998)

Krystek, U., Herzhoff, M.: Szenario-Technik und Frühaufklärung: Anwendungs-stand und Integrationspotential. Zeitschrift für Controlling und Management 50(5), 305-310 (2006)

Lenz, R.T., Engledow, J.L.: Environmental Analysis Units and Strategic Decision-making: a Field Study of Selected "Leading-edge" Corporations. Strategic Management Journal 7(1), 69-89 (1986)

Lesca, N., Caron-Fasan, M.-L.: Strategic scanning project failure and abandonment factors: Lessons learned. European Journal of Information Systems 17(4), 371-386 (2008) 
Makridakis, S., Hogarth, R.M., Gaba, A.: Why Forecasts Fail. What to Do Instead. MIT Sloan Management Review 51(2), 83-90 (2010)

Mayer, J.H.: Managing the Future-Six Guidelines for Designing Environmental Scanning Systems. In: Jain, H., Sinha, A.P., Vitharana, P. (eds.) DESRIST 2011. LNCS, vol. 6629, pp. 276-290. Springer, Heidelberg (2011)

Mayer, J.H.: Organisatorische Veränderungen durch die aktuelle Wirtschaftskrise - Bestandsaufnahme und Implikationen für Unternehmenssteuerungssysteme. In: Proceedings des 25. Deutschen Controlling Congresses, Dortmund, Deutschland, pp. 209-228 (2010)

Mayer, J.H., Wurl, H.-J.: Strategische Früherkennung in internationalen Konzernen, pp. 1-28. University of St. Gallen, St. Gallen (2011)

MIS Journal Ranking (AIS 2007), http: / / ais.affiniscape.com/displaycommon. cfm?an=1\&subarticlen br $=432$ (accessed January 17, 2011)

Narchal, R.M., Kittappa, K., Bhattacharya, P.: An Environmental Scanning System for Business Planning. Long Range Planning 20(6), 96-105 (1987)

Paech, B., Kerkow, D.: Non-Functional Requirements Engineering - Quality is Essential. In: 10th Anniversary International Workshio on Requirements Engineering: Foundation for Software Quality (REFSQ 2004), Riga, Latvia, pp. 27-40 (2004)

Power, D.J.: Decision Support Systems: A Historical Overview. Springer, Berlin (2008)

Rockfellow, J.D.: Wild Cards Preparing for "The Big One". The Futurist 28(1), 14-19 (1994)

Sherman, W.S., Chambers, V.: SOX as Safeguard and Signal: The Impact of The SarbanesOxley Act of 2002 on US Corporations' Choice to List Abroad. The Multinational Business Review 17(3), 163-179 (2009)

Taleb, N.N., Goldstein, D.G., Spitznagel, M.W.: The Six Mistakes Executives Make in Risk Management. Harvard Business Review 87(10), 78-81 (2009)

Urbach, N., Smolnik, S., Riempp, G.: The State of Research on Information Systems Success A Review of Existing Multidimensional Approaches. Business \& Information Systems Engineering (BISE) 1(4), 315-325 (2009)

Vom Brocke, J., Simons, A., Niehaves, B., Riemer, K., Plattfaut, R., Cleven, A.: Reconstructing the Giant: On the Importance of Rigour in Documenting the Literature Search Process. In: 17th European Conference on Information Systems (ECIS), Verona, Italy, pp. 22062217 (2009)

Walls, J.G., Widmeyer, G.R., El Sawy, O.A.: Building an Information System Design Theory for Vigilant EIS. Information Systems Research 3(1), 36-59 (1992)

Webster, J., Watson, R.T.: Analyzing the Past to Prepare for the Future: Writing a Literature Review. MIS Quarterly 26(2), xiii-xxiii (2002)

Wixom, B.H., Watson, H.J.: The BI-based organization. International Journal of Business Intelligence 1(1), 13-28 (2010)

WKWI. WI-Liste der Konferenzen. Wirtschaftsinformatik 50(2), 155-163 (2008)

Xu, X.M., Kaye, G.R., Duan, Y.: UK executives vision on business environment for information scanning A cross industry study. Information \& Management 40(5), 381-389 (2003)

Yasai-Ardenaki, M., Nystrom, P.C.: Designs for Environmental Scanning Systems: Tests of a Contingency Theory. Management Science 42(2), 187-204 (1996) 
Table A1. Full list of researched articles

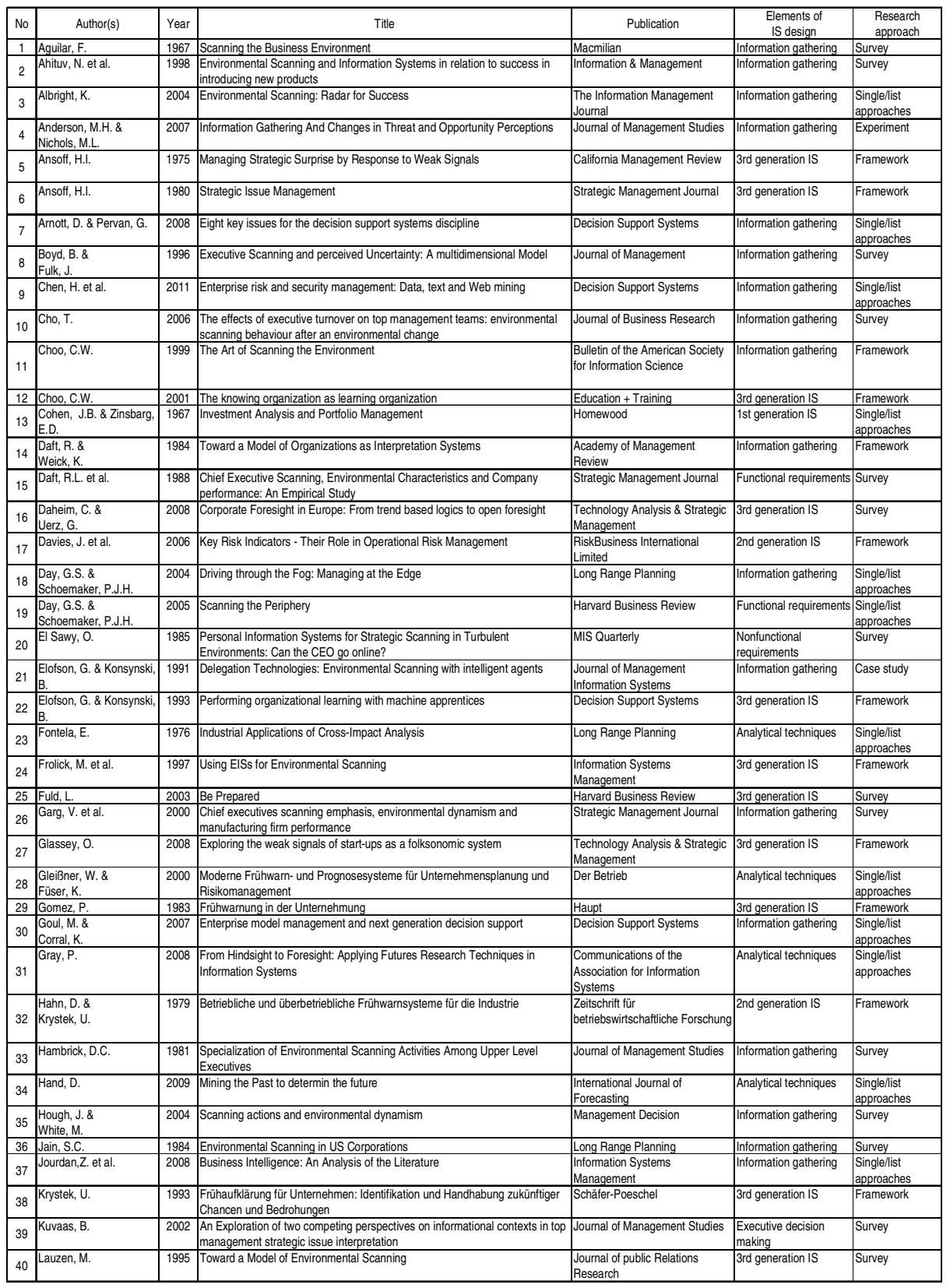


Table A1. (Continued)

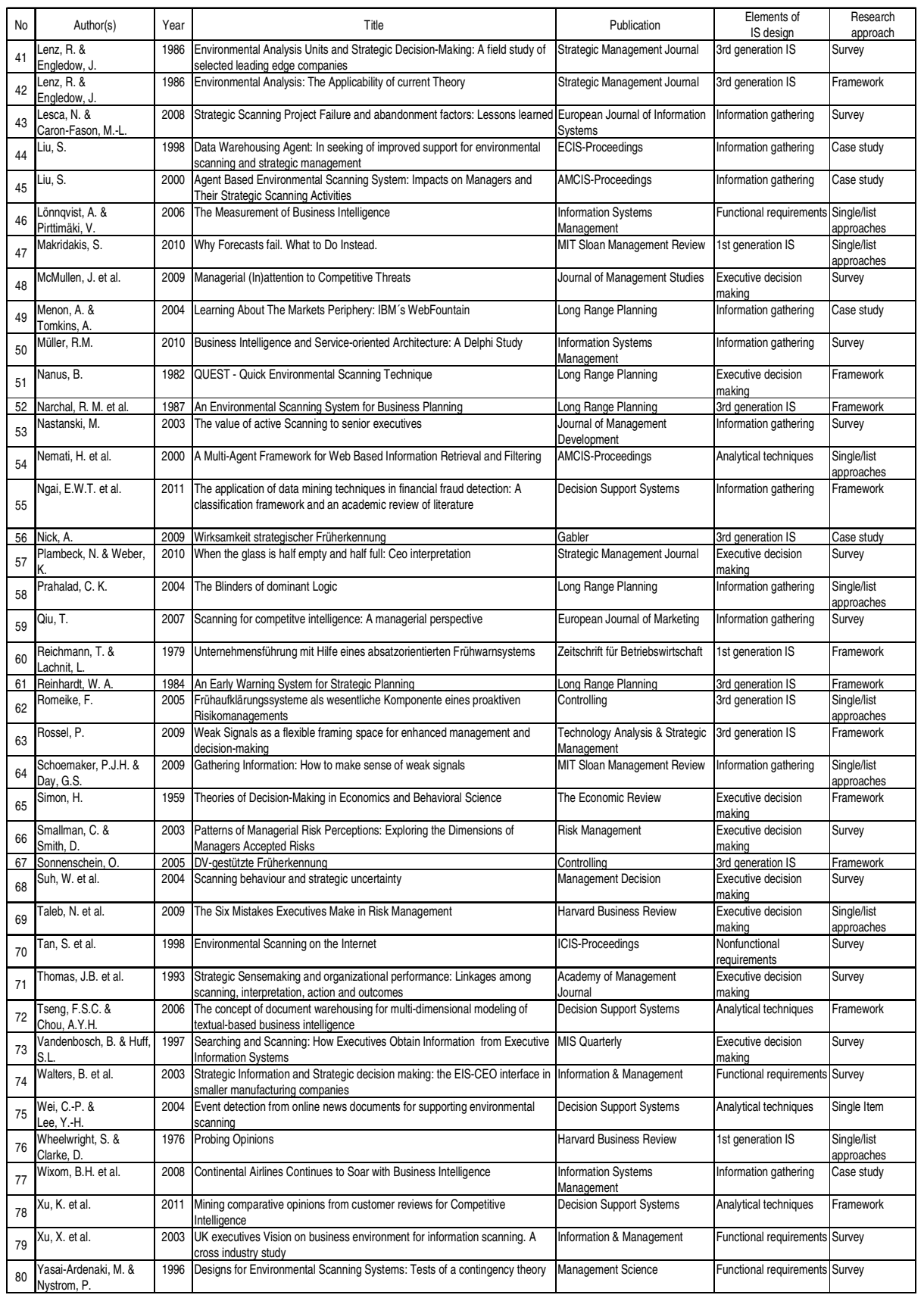

